\title{
CONSIDERACIONES CLÍNICAS Y REGULACIÓN DEL EQUILIBRIO ÁCIDO-BASE EN GANADO BOVINO
}

\section{CLINICAL CONSIDERATIONS AND REGULATION OF ACID-BASE BALANCE IN CATTLE}

\author{
Johann R. Baquero-Parrado ${ }^{1}$
}

\begin{abstract}
RESUMEN
El entendimiento de los disturbios electrolíticos y ácidobase depende de la comprensión de los mecanismos fisiológicos que los regulan y de la interpretación de los cambios en el $\mathrm{pH}$ sanguíneo. Algunas enfermedades producen un patrón constante de pérdidas de fluidos y electrolitos con cambios predecibles en el volumen y la concentración. Además, uno o más de los componentes que los regulan pueden estar comprometidos, lo cual, puede resultar en desórdenes del estado ácido-base. Actualmente existen tres enfoques para la evaluación clínica del estado ácido-base: la ecuación de HendersonHasselbach, el modelo de iones fuertes y el modelo de iones fuertes simplificado, quedando a consideración del clínico su utilización. La manipulación de la diferencia entre cationes y aniones en la dieta (DCAD) es definida como los mili-equivalentes de $(\mathrm{Na}+\mathrm{K})-(\mathrm{Cl}+\mathrm{S})$ por kilogramo $(\mathrm{mEq} / \mathrm{kg})$ de materia seca (MS) y tiene un impacto directo sobre el estado ácido-base, siendo el cloruro de amonio la sal con más poder acidificante y el sulfato de magnesio la sal aniónica más palatable, teniendo en cuenta que el $\mathrm{pH}$ urinario es una herramienta útil para evaluar el grado de acidosis metabólica impuesto por las sales aniónicas. Los valores de laboratorio interpretados por cualquier modelo son solo un paso en el análisis electrolítico y ácido-base del paciente. Para tomar decisiones racionales, se deben correlacionar estos valores con el cuadro clínico y el conocimiento de la bioquímica y fisiología subyacente, utilizando los
\end{abstract}

\footnotetext{
${ }^{1}$ MVZ, Esp. Grupo Prevención y Análisis de Riesgos Zoosanitarios y Asuntos Internacionales, Seccional Valle del Cauca, Dirección para correspondencia: Calle 73 No. 8A-35, Barrio Andrés Sanín, Cali. E-mail: johann. baquero@ica.gov.co
}

importantes principios de la medicina, basada en la evidencia.

Palabras clave: Bicarbonato, equilibrio ácido-base, ganado bovino, ión hidrógeno, $\mathrm{pH}$.

\section{SUMMARY}

Understanding the electrolyte and acid-base disorder depends on the comprehension of the physiological mechanisms which regulates them, and the interpretation of changes in blood $\mathrm{pH}$. Some diseases produce a constant pattern of electrolyte and fluid loss with foreseeable changes in electrolyte concentration and fluid volume. Furthermore, one or more of the regulatory components may become compromised, resulting in disorders of the acid-base status. Currently there are three approaches to the clinical assessment of acidbase status: the Henderson-Hasselbach equation, the strong ion model and the simplified strong ion model, dependent its use on considerations of the professional. The manipulation of the dietary cation-anion difference (DCAD) is defined as the m-equivalents of $(\mathrm{Na}+\mathrm{K})$ $(\mathrm{Cl}+\mathrm{S})$ by kilogram $(\mathrm{mEq} / \mathrm{kg})$ of dry matter $(\mathrm{DM})$ It has a direct effect on the acid-base status, being ammonium chloride the most acidifying salt and magnesium sulfate the most palatable anionic salt, taking in count that urinary $\mathrm{pH}$ is a useful tool to assess the degree of metabolic acidosis imposed by the anionic salts. Laboratory values are just one step in an electrolyte and acid-base analysis of patient. To make rational decisions these values must be correlated with the clinical picture and the knowledge of the underlying biochemistry and physiology, using the important principles of evidence-based medicine.

Key words: Bicarbonate, acid-base balance, cattle, hydrogen ion, $\mathrm{pH}$. 


\section{INTRODUCCIÓN}

Las alteraciones del estado ácido-base son comunes en ganado bovino y su evaluación de laboratorio comprende la determinación de la concentración de hidrógeno $\left[\mathrm{H}^{+}\right]$, la concentración de bicarbonato $\left[\mathrm{HCO}_{3}^{-}\right]$y la tensión de dióxido de carbono en el plasma $\left(\mathrm{PCO}_{2}\right)$, entre otros parámetros. Dentro de los productos del metabolismo del organismo animal, se encuentra el ion hidrógeno, el cual es mantenido dentro de un estrecho margen por interacciones bioquímicas de los sistemas que lo regulan, bien sea deshaciéndose del ion $\mathrm{H}^{+}$(excretándolo directamente o uniéndolo a buffers) o conservando $\mathrm{HCO}_{3}$. Esta revisión ofrece algunos elementos de juicio que el clínico puede usar para estimar los disturbios del equilibrio ácido-base del ganado bovino, de acuerdo a las investigaciones realizadas sobre el área.

\section{Modelos utilizados para la evaluación del estado ácido-base}

La Ecuación de Henderson- Hasselbach data desde 1916 (Hasselbach, 1916), siendo el modelo más utilizado en la práctica clínica. Tradicionalmente, el equilibrio ácido-base es considerado en términos de $\mathrm{pH}$. Dado que el $\mathrm{pH}$ es el logaritmo negativo de $\left[\mathrm{H}^{+}\right]$, la ecuación de Henderson - Hasselbach es expresada como: $\mathrm{pH}=\mathrm{pK}+\log \left[\mathrm{HCO}_{3}^{-}\right] / S \times \mathrm{PCO}_{2}$, donde $\mathrm{pK}$ es el logaritmo de una constante de disociación y $S$ un factor de solubilidad que convierte la $\mathrm{PCO}_{2}$ en moles/L (Michell et al. 1991).

De igual manera, la Ecuación de Henderson - Hasselbach utiliza: el pH (parámetro general del estado ácido-base), la $\mathrm{PCO}_{2}$ (medición independiente del componente respiratorio del balance ácido-base) y el exceso de base extracelular (medición independiente del componente metabólico) del estado ácido-base. No obstante, el nivel de $\mathrm{HCO}_{3}{ }^{-}$actual, el $\mathrm{HCO}_{3}{ }^{-}$estándar, el dióxido de carbono $\left(\mathrm{CO}_{2}\right)$ total, el exceso de base extracelular (Astrup et al. 1960) y el cambio en la base buffer neutralizadora también se han utilizado para caracterizar el componente metabólico. Esta ecuación caracteriza cuatro disturbios primarios del estado ácido-base: acidosis respiratoria $\left(\mathrm{PaCO}_{2}\right.$ incrementada), alcalosis respiratoria $\left(\mathrm{PaCO}_{2}\right.$ reducida), acidosis metabólica (reducción del exceso de base extracelular) o alcalosis metabólica (incremento del exceso de base extracelular) (Figura 1).

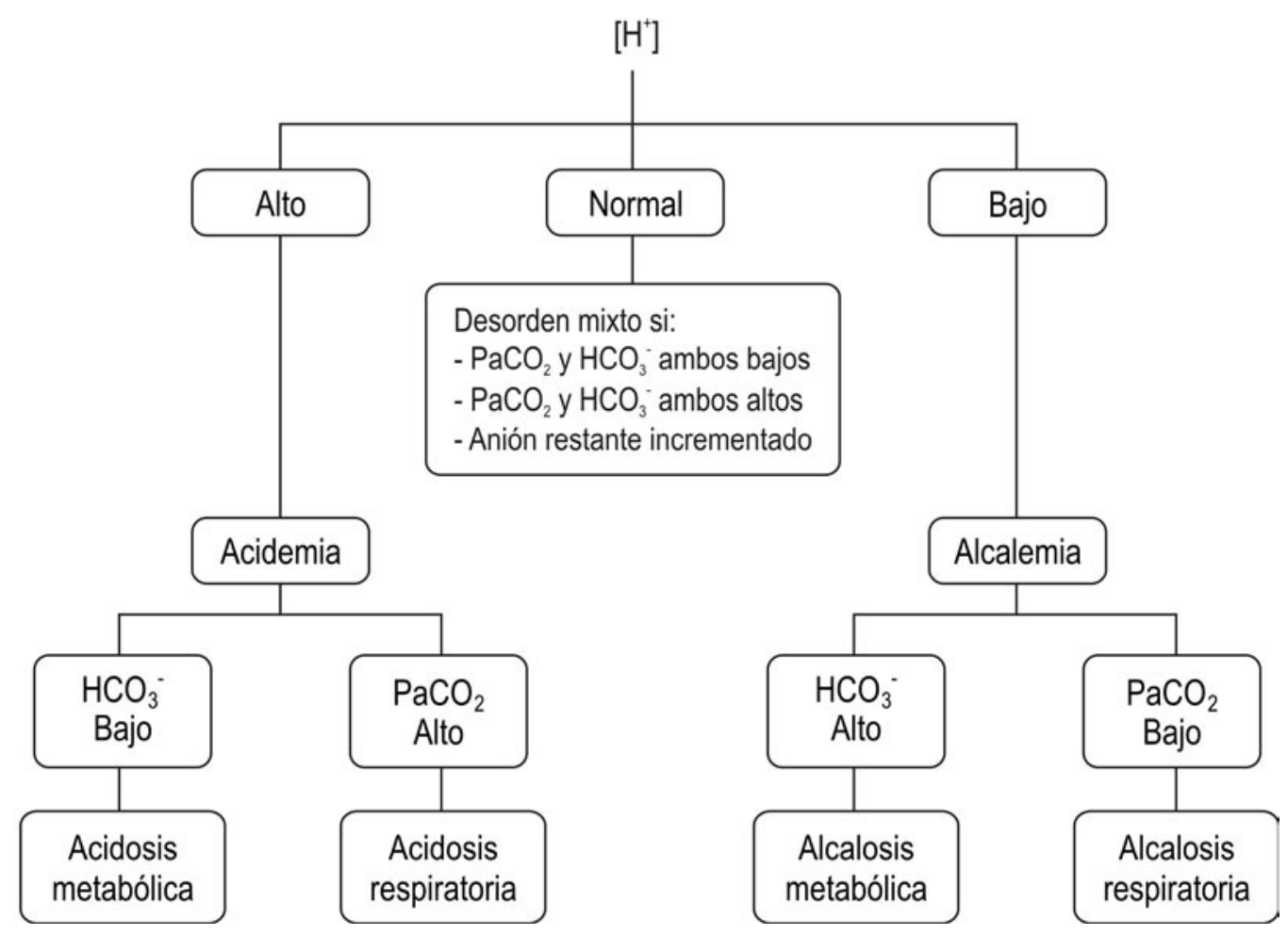

Figura 1. Diagnóstico inicial de los disturbios ácido-base (Modificado de Halperin \& Goldstein, 1999). 
Según este modelo existe una relación causa-efecto entre el $\mathrm{HCO}_{3}{ }^{-}$y el hidrógeno $\left(\mathrm{H}^{+}\right)$. Según esta teoría, la causa de la acidosis metabólica estaría en una reducción de la capacidad tampón del $\mathrm{HCO}_{3}{ }^{-}$, con lo que el $\mathrm{H}^{+}$libre (no tamponado) reduce el $\mathrm{pH}$. En consecuencia con lo anterior, las causas de acidosis metabólica tienen en común una reducción del $\mathrm{HCO}_{3}{ }^{-}$.

Como causas más frecuentes de acidosis metabólica $\left(\mathrm{pH}<7,35\right.$ y $\left.\left[\mathrm{HCO}_{3}{ }^{-}\right]<20 \mathrm{mmol} / \mathrm{L}\right)$, se encuentran la diarrea neonatal, la acidosis ruminal, la administración parenteral excesiva de $\mathrm{NaCl}$, el choque endotóxico, la hipovolemia, el ptialismo o disfagia y enfermedades, como babesiosis (Babesia divergens) (Sherlock et al. 2003), metritis, cetosis, mastitis aguda, entre otras. Los terneros con concentraciones elevadas de D-lactato no necesitan terapia específica, pues estas disminuyen al corregir la acidosis y al restaurar el volumen de fluidos corporales (Lorenz E Vogt, 2006; BaqueroParrado E Fuentes-Reyes, 2007). Las variaciones en el comportamiento, la postura y el reflejo palpebral pueden ser mejor explicados por las elevadas concentraciones de D-lactato que por la disminución en el exceso de base (Kasari E Naylor, 1986; Lorenz, 2004).

La alcalosis metabólica (incremento del exceso de base extracelular, $\mathrm{pH}>7,45$ ) es comúnmente hallada en bovinos con: estenosis pilórica, intususcepción del intestino delgado, intususcepción del intestino grueso, impactación cecal, impactación abomasal, timpanismo y torsión abomasal en terneros, intususcepción cecal en terneros, desplazamiento del abomaso, vólvulo abomasal, hiperadronocorticismo y por la administración de óxido de magnesio. El cuadro clínico severo de anaplasmosis (Anaplasma marginale) conduce a desórdenes mixtos (Castañeda et al. 2002). Los becerros lactantes presentan alcalosis transitoria post-prandial (Lisbôa et al. 2003).

La acidosis respiratoria $\left(\mathrm{PaCO}_{2}\right.$ incrementada $>45 \mathrm{~mm}$ $\mathrm{Hg}$ ), se presenta al nacimiento y en algunas enfermedades del sistema respiratorio, tales como: neumonía, enfisema, edema pulmonar, efusión pleural. Algunas alteraciones neuromusculares, la hernia diafragmática, la depresión del Sistema Nervioso Central (SNC), la intoxicación por barbitúricos y la disminución en el gasto cardíaco conllevan, también, a la presencia de acidosis respiratoria, mientras que la alcalosis respiratoria $\left(\mathrm{PaCO}_{2}\right.$ reducida $<35 \mathrm{~mm} \mathrm{Hg}$ ) es común hallarla en situaciones de hipoxia, encefalopatía hepática, excitación del SNC y choque de calor.

De otra parte y de acuerdo al Modelo de Iones Fuertes (Stewart, 1983), las concentraciones de $\mathrm{H}^{+} \mathrm{y} \mathrm{HCO}_{3}{ }^{-}$son dependientes de las concentraciones de las variables independientes o primarias, es decir: $\mathrm{PCO}_{2}$, ácidos débiles totales o proteínas y iones fuertes (Stewart, 1983; Funk, 2007, Quintard et al. 2007), dado que en los fluidos biológicos y los electrolitos fuertes, como el sodio $\left(\mathrm{Na}^{+}\right)$, el potasio $\left(\mathrm{K}^{+}\right)$y el cloro $(\mathrm{Cl})$ están completamente disociados y su constante de disociación (K) es ignorada por estar completamente disociados; mientras que los electrolitos débiles, como las proteínas, el agua y el $\mathrm{CO}_{2}$, se disocian ó ionizan parcialmente (Stewart, 1983; Rehm et al. 2004).

La diferencia de cargas entre cationes fuertes y aniones fuertes completamente disociados en el plasma es estimada así: $\left(\left[\mathrm{Na}^{+}\right]+\left[\mathrm{K}^{+}\right]+\left[\right.\right.$calcio- $\left.\mathrm{Ca}^{+2}-\right]+[$ magnesio $\left.\left.-\mathrm{Mg}^{2+}-\right]\right)-\left(\left[\mathrm{Cl}^{-}\right]+[\right.$otros aniones fuertes: $\left.\mathrm{A}]\right)=44 \mathrm{mEq} / \mathrm{l}$ en plasma en terneros (Constable $\mathcal{E}$ Staempfli, 2004), y $40 \mathrm{mEq} / \mathrm{L}$ en rumiantes adultos, aproximadamente (Staempfli, 2005). Este exceso de cargas positivas, se denomina Diferencia de Iones Fuertes (DIF) (Stewart, 1983) y está siempre balanceado por una cantidad igual de "base buffer", principalmente, fosfato, albúmina y $\mathrm{HCO}_{3}$.

Así, los cambios en el pH de los líquidos biológicos solo se pueden producir como consecuencia de la modificación de una o varias de las variables independientes. En efecto, el cambio en la concentración de $\mathrm{H}^{+}$, se debe a cambios en la disociación del agua, ocasionados por modificaciones en las variables independientes; siendo la concentración de ión $\mathrm{H}^{+}$una variable dependiente y encontrándose en una asociación no-lineal con $\mathrm{PCO}_{2}$ (matemáticamente, una función polinomial del cuarto orden) (Whitehair et al. 1995; Staempfli, 2005). Una anormalidad primaria del estado ácido-base, se debe a un cambio en una o más variables independientes en el plasma. Más de una alteración primaria podría estar presente con efectos aditivos u opuestos. Los cambios compensatorios ocurren en respuesta a alteraciones primarias. En tales compensaciones, la DIF o la $\mathrm{PCO}_{2}$ son reguladas en respuesta al estado ácido-base del paciente, mientras la albúmina, no. Estos cambios compensatorios únicamente involucran cambios en DIF o $\mathrm{PCO}_{2}$. La DIF es regulada por el riñón y la $\mathrm{PCO}_{2}$ 
es regulada por el sistema respiratorio. Una alteración primaria en DIF podría resultar en una alteración secundaria en $\mathrm{PCO}_{2}$ (compensación respiratoria) y una alteración primaria en $\mathrm{PCO}_{2}$ podría resultar en un cambio secundario en la DIF (compensación renal) (Whitehair et al. 1995).

A pesar de esto, el modelo de iones fuertes de Stewart no suministra un método práctico tanto para la determinación de concentración plasmática total de buffer o neutralizadores débiles no volátiles $\left[A_{t o t}\right]$ (como albúmina, globulina y fosfato), como para la determinación de la constante de disociación de equilibrio efectivo para los ácidos débiles no viables del plasma $\left(\mathrm{K}_{\mathrm{a}}\right)$, además, que requiere de un valor exacto para precisar la $\left[\mathrm{DIF}^{+}\right]$, mediante la determinación y cuantificación de todos los iones fuertes en el plasma, lo cual, es muy complicado, ya que iones fuertes no identificados presentes, tales como lactato- (acidosis ruminal), sulfato $-\mathrm{SO}^{-2}$ - (uremia), $\beta-\mathrm{OH}$ butirato $^{-} \mathrm{y}$ acetoacetato (cetoacidosis) pueden estar incrementados en concentraciones de $\mathrm{mEq} / \mathrm{L}$ en rumiantes enfermos.

Una baja DIF resulta en acidosis (incremento en $\left[\mathrm{H}^{+}\right]$) y puede ser causada por una disminución en $\left[\mathrm{Na}^{+}\right]$o un aumento en $\left.\mathrm{Cl}^{-}\right]$o aniones no identificados. Una alta DIF resulta en alcalosis y puede ser causada por un aumento en $\left[\mathrm{Na}^{+}\right]$o una disminución en $\left[\mathrm{Cl}^{-}\right]$(Whitehair et al. 1995). La respuesta buffer comienza al principio del desorden y es proporcional a la magnitud de la alteración (Oliver, 1998).

Desde el punto de vista clínico, el modelo de iones fuertes es invaluable, ya que ofrece una nueva manera acerca de la fisiopatología de los desórdenes mixtos del estado ácido-base (Whitehair et al. 1995; Quintard et al. 2007), en particular, de los efectos de la hipoproteinemia e hiperproteinemia sobre el estado ácido-base, explicables únicamente por los modelos de iones fuertes (Wilkes, 1998).

Por último, el Modelo de Iones Fuertes Simplificado asegura que los componentes plasmáticos actúan como iones fuertes $\left(\mathrm{DIF}^{+}\right)$, iones buffer volátiles $\left(\mathrm{HCO}_{3}{ }^{-}\right)$o iones buffer no volátiles (A') (Constable, 1997). Siempre, la concentración de iones fuertes [ $\mathrm{DIF}^{+}$] equipará a la suma de la concentración del ion buffer bicarbonato $\left[\mathrm{HCO}_{3}{ }^{-}\right]$ más la concentración del ion buffer no volátil $\left[\mathrm{A}^{-}\right]$, de manera que $\left[\mathrm{DIF}^{+}\right]-\left[\mathrm{HCO}_{3}{ }^{-}\right]-\left[\mathrm{A}^{-}\right]=0$, para mantener la electro-neutralidad (Figura 2). La ecuación asume que todos los componentes ionizados plasmáticos se pueden clasificar como un ion fuerte $\left(\mathrm{DIF}^{+}\right)$, un ion buffer volátil $\left(\mathrm{HCO}_{3}{ }^{-}\right)$o un ion buffer no volátil (A). Esta es la teoría que fundamenta el modelo de iones fuertes simplificado.

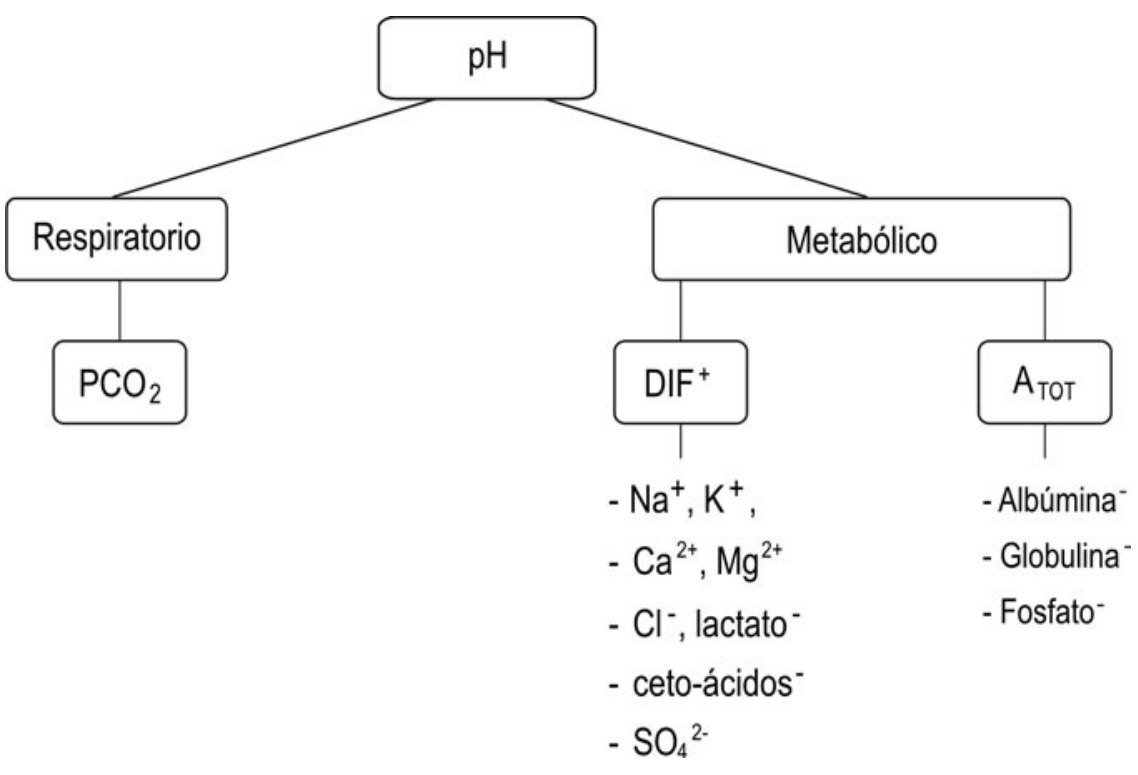

Figura 2. Determinantes del pH sanguíneo, según el modelo de iones fuertes simplificado. Ambos, [ATOT] y [DIF+] son mediciones independientes del componente no respiratorio (metabólico) del pH sanguíneo (Constable, 2000). 
Los valores para $\left[\mathrm{A}_{\mathrm{TOT}}\right.$ ] y $\mathrm{K}_{\mathrm{a}}$ han sido determinados en terneros Holstein (Staempfli et al. 1994; Constable E Staempfli, 2004); bovinos adultos (Constable, 2002) $\mathrm{y}$ en equinos (Constable, 1997) siendo el $\mathrm{pK}_{\mathrm{A}}$ de la albúmina sérica bovina de 5,5Eq/L (Staemfpli et al. 1994) y la osmolalidad en plasma normal en rumiantes de, aproximadamente, $285 \mathrm{mOsm} / \mathrm{kg}$, mientras que la osmolaridad está en 306mOsm/L (Constable, 2003). Se recomienda utilizar este modelo ante concentraciones anormales de proteínas plasmáticas totales (PPT), albúmina y fosfato (Tabla 1). La utilidad clínica de los modelos que utilizan la cuantificación del estado ácidobase está determinada en la capacidad para describir su fisiología y por la facilidad de la medición de los parámetros modelo-independientes, ya que basándose sobre principios fisicoquímicos identifica y cuantifica los componentes individuales de las anormalidades ácido-base complejas y proporciona ideas sobre sus patogénesis (Whitehair et al. 1995; Fencl et al. 2000).

Tabla 1: Categorización de iones simples en plasma de bovino adulto en muestras de sangre venosa (Constable, 2002).

\begin{tabular}{|c|c|c|c|}
\hline IONES FUERTES & $(\mathrm{mEq} / \mathrm{L})$ & & $(\mathrm{mEq} / \mathrm{L})$ \\
\hline Cationes & & Aniones: & \\
\hline Sodio & 144,0 & Cloro & 104,0 \\
\hline Potasio & 4,5 & Sulfato & 1,6 \\
\hline Calcio & 4,5 & L-lactato & 0,9 \\
\hline Magnesio & 1,7 & $\beta$-hidroxibutirato & 0,8 \\
\hline Amonio & 0,1 & Acetoacetato & 0,2 \\
\hline Cationes totales & 154,8 & Ácidos grasos no esterificados & 0,4 \\
\hline \multirow{5}{*}{$\begin{array}{l}\text { IONES BUFFER } \\
\text { Aniones volátiles: } \\
\text { Bicarbonato }\end{array}$} & \multirow{5}{*}{$\begin{array}{c}(\mathrm{mEq} / \mathrm{L}) \\
26,4\end{array}$} & Acetato & 1,5 \\
\hline & & Propionato & 0,08 \\
\hline & & Butirato & 0,04 \\
\hline & & Urato & 0,5 \\
\hline & & Succinato & 0,5 \\
\hline Aniones no volátiles: & & Piruvato & 0,1 \\
\hline Proteína & 14,6 & Aniones totales & 110,6 \\
\hline Fosfato & 2,9 & & \\
\hline Citrato & 0,2 & & \\
\hline Aniones no volátiles totales & 17,7 & & \\
\hline
\end{tabular}

Toma de muestras para la evaluación: La sangre, se puede obtener de la arteria braquial en terneros recién nacidos (Adams et al. 1991), de la vena yugular, de la vena mamaria (Benjamín, 1991), de la vena metacarpiana volar superficial (Szenci, 1985) y de la vena coccígea. Los valores de $\mathrm{pH}, \mathrm{PCO}_{2}$ y $\mathrm{PO}_{2}$ pueden ser más bajos o más altos en muestras obtenidas de la vena coccígea, frente a otras de sangre venosa en vacas lecheras posparto, clínicamente saludables (Bajcsy et al. 1999). La mejor hora para colectar las muestras de sangre es alrededor de 12 a 24 horas luego del parto para detectar posible hipocalcemia (Oetzel, 2004) y se recomienda la determinación inmediata de la concentración de $\mathrm{Ca}^{2+}$ ionizado, para evitar lecturas erróneas (Roeder \& Clark, 1995, Szenci et al. 1991), pues la hemólisis incrementa y disminuye falsamente los valores séricos de $\mathrm{K}^{+}$y $\mathrm{Na}^{+}$, respectivamente (Roussel et al. 1997).

En el estudio de la hipopotasemia sí se recomienda tomar las muestras diariamente y la misma hora (Sattler et al. 2001). Para la determinación de la acidosis metabólica, el aparato Harleco es útil, pues a partir de la $\mathrm{PCO}_{2}$, se mezclan el ácido láctico y el suero, convirtiendo el $\mathrm{HCO}_{3}{ }^{-}$en ácido carbónico $\left(\mathrm{H}_{2} \mathrm{CO}_{3}\right)$ (Naylor, 1987), pero el aparato Harleco es menos efectivo con muestras alcalóticas (Groutides \& Michell, 1990). 
En cuanto al $\mathrm{pH}$ del fluido ruminal, se recomienda la obtención de la muestra, mediante ruminocentesis, puesto que las muestras obtenidas a través de sondas estomacales, se "contaminan" con pequeñas cantidades de saliva, la cual, contiene $\mathrm{HCO}_{3}$, causando errores en la lectura (Dirksen E Smith, 1987). El pH del líquido ruminal varía según el tipo de alimento y el tiempo transcurrido desde la última comida hasta la toma de la muestra, siendo el intervalo normal de 6,2 a 7,2. Con todo y lo anterior, el $\mathrm{pH}$ se debe medir inmediatamente después de tomar la muestra y, para lo cual, se sugiere el uso del pHmetro portable (Geishauser $E$ Mannhardt, 1994; Nappert $\&$ Naylor, 2001). En casos de putrefacción proteica o cuando la muestra se ha mezclado con saliva, se pueden observar valores de $\mathrm{pH}$ incrementados $(8,0-10,0)$, mientras que valores bajos se observan tras la ingestión de carbohidratos. Un valor inferior a 5,0 indica lactoacidosis ruminal y este nivel se mantendrá entre 6 y 24 horas después que el animal haya ingerido la dieta con carbohidratos (Radostitis et al. 2002). En las dietas típicas para vacas lactantes, el $\mathrm{pH}$ ruminal puede ser más bajo en muestras recolectadas, mediante ruminocentesis, que en muestras recolectadas, a través de cánula ruminal (Garret et al. 1999).

Se podría considerar además, en la evaluación del paciente, el compromiso renal, pues la hipovolemia, la deshidratación y la endotoxemia, presentes en muchas enfermedades, afectan la función renal (Constable et al. 1991). El monitoreo seriado de creatinina (Constable, 1991; (Ulutas \& Sahal, 2005) y de excreción fraccional de electrolitos podría ser un indicador razonable de la filtración glomerular y remoción de electrolitos por parte de los riñones (Neiger $\mathcal{E}$ Hagemoser, 1985; Fleming et al. 1991), sin que la edad y la categoría de producción de leche (alta, media y baja) influyan en la excreción fraccional de electrolitos (Fleming et al. 1992).

Parámetros habituales de evaluación: Existen otros parámetros aparte del pH sanguíneo para la evaluación de estado ácido-base, diseñados para reflejar su efecto, pero no su causa, tales como los gases sanguíneos arteriales y venosos $\left(\mathrm{PO}_{2}, \mathrm{PCO}_{2}\right)$, bicarbonato estándar, anión restante - anión gap - y el exceso de base.

Gases sanguíneos: La presión arterial de dióxido de carbono $\left(\mathrm{PaCO}_{2}\right)$ refleja la concentración de $\mathrm{CO}_{2}$ en el aire alveolar requerida para el equilibrio entre la producción de $\mathrm{CO}_{2}$ (metabolismo) y la remoción de $\mathrm{CO}_{2}$ (ventilación). Los terneros recién nacidos (una hora de edad) muestran los siguientes valores en gases arteriales de: $\mathrm{pH}$ entre 7,25 y 7,$35 ; \mathrm{pCO}_{2}$ entre 45,13 y $55,67 \mathrm{~mm}$ $\mathrm{Hg}$ y entre 20,74 y $26,30 \mathrm{mEq} / \mathrm{L}$ de $\mathrm{HCO}_{3}{ }^{-}$(Adams et al. 1991).

La sangre venosa es adecuada para realizar interpretaciones válidas de las alteraciones ácido-base de posible origen metabólico (Carlson 1989), mientras que la sangre arterial es apropiada para evaluar los parámetros respiratorios $\left(\mathrm{PaO}_{2}, \mathrm{PaCO}_{2}\right.$, ó $\mathrm{CO}_{2}$ total $)$ (Kasari, 1999; Bleul et al. 2007). En las últimas horas antes del parto, la presión parcial de oxígeno y el pH sanguíneo fetal se elevan (Wilson et al. 1977), mientras que la glucosa sanguínea presenta valores más bajos (Tyler E Ramsey, 1991).

Bicarbonato estándar: Se define como la $\left[\mathrm{HCO}_{3}^{-}\right]$en $\mathrm{mEq} / \mathrm{L}$ del plasma cuando la sangre oxigenada normal se equilibra a $37^{\circ} \mathrm{C}$, con una mezcla de gas, que tiene una $\mathrm{PCO}_{2}$ de $40 \mathrm{~mm} \mathrm{Hg}$. Es la mejor herramienta para estimar la base buffer en sangre porque es independiente de los cambios de $\mathrm{PCO}_{2}$ e ignora la contribución de los buffers no volátiles (albúmina, fosfato, globulina, $\mathrm{Hb}^{-}$) a los cambios de la neutralización del pH (Stockhman $\varepsilon$ Scott, 2002). Cabe anotar que las vacas a altitud moderadamente alta $(3000 \mathrm{~m})$ presentan concentraciones $\left[\mathrm{HCO}_{3}{ }^{-}\right]$plasmáticas más bajas que las vacas que se encuentran a nivel del mar (Ramírez et al. 1992).

Anión restante - anión gap -: Se utiliza para detectar la presencia de cationes y aniones no medidos en el plasma $\left(\mathrm{SO}_{4}{ }^{-2},-\mathrm{Ca}^{+2,} \mathrm{Mg}^{2+}\right)$, iones buffer no volátiles (proteínas y fosfatos) y ácidos orgánicos (lactato-, ß-OH butirato-, acetoacetato-) (Feldman E Rosenberg, 1981; Winter et al. 1990; Ewaschuk et al. 2003) y se calcula de la diferencia entre la sumatoria de los cationes medidos, menos la sumatoria de los aniones medidos en el plasma sanguíneo $\left(\left[\mathrm{Na}^{+}\right]+\left[\mathrm{K}^{+}\right]\right)-\left(\left[\mathrm{Cl}^{-}\right]+\left[\mathrm{HCO}_{3}^{-}\right]\right)$(Gabow et al. 1980). El anión restante puede estar enmascarado por cambios en las concentraciones séricas de proteínas (en especial albúmina y fosfato) (Gabow, 1985; Kraut $\mathcal{E}$ Madias, 2007), así como las variables independientes también cambian el anión restante porque el $\mathrm{HCO}_{3}^{-}$es una variable independiente $\left(\mathrm{HCO}_{3}^{-}\right)$y es tenido en cuenta para su cálculo (Whitehair et al. 1995).

En efecto, el anión restante es clínicamente útil para la estimación de la concentración de lactato en el plasma 
en equinos y en bovinos (Constable et al. 1997) con concentraciones "normales" de PPT. Sin embargo, el anión restante tiene una correlación significativa, con la concentración sérica total de D-Lactato, mas no con la concentración sérica de L-Lactato (Ewaschuk et al. 2003). Generalmente, un anión restante elevado es causado por la acumulación de ácidos orgánicos (ácido láctico y cetoácidos). Es menos común un anión restante disminuido, atribuible a la hipoalbuminemia y a acidosis metabólica hiperclorémica (Roussel et al. 1997). Bovinos con vólvulo abomasal y un anión restante de $30 \mathrm{mEq} / \mathrm{L}$ o superior tienen un pobre pronóstico de supervivencia (Garry et al. 1985).

Exceso de Base: Se expresa como el exceso de base extracelular en sangre entera (Astrup et al. 1960) influenciado, principalmente, por las concentraciones de $\mathrm{Cl}^{-}$y aniones identificados en sangre -terneros-, mientras que el $\mathrm{Na}^{+}$y la de PPT tienen un efecto menor, siendo su valor de $+3,4 \mathrm{mEq} / \mathrm{L}$ en terneros (Stocker et al. 1999). El cambio en el exceso de base neta, debida a anormalidades de agua libre o cambio en el contenido de agua, es reflejada en el $\mathrm{Na}^{+}$plasmático (Whitehair et al. 1995).

El exceso de base disminuye $2,9 \mathrm{mEq} / \mathrm{L}$ por cada incremento de $1 \mathrm{~g} /$ dl en la concentración de PPT (Figge et al. 1991); es un indicador adecuado del componente no respiratorio -metabólico- de una alteración del equilibrio ácido-base, no afectado por los cambios agudos en la $\mathrm{PCO}_{2}$ y se refiere, directamente, al espacio de distribución del bicarbonato sódico $\left(\mathrm{NaHCO}_{3}\right)$. A pesar de esto, el valor del exceso de base calculado supone una concentración sérica de PPT constante y normal (7,2g/dl) (Constable, 1999) y no debe ser usada como un criterio único para determinar si una vaca con vólvulo abomasal deba ser tratada o sacrificada (Simpson et al. 1985).

Aunque existen nomogramas y fórmulas matemáticas para calcular el exceso de base a partir de los valores medidos en sangre de $\mathrm{pH}, \mathrm{PCO}_{2}$ y concentración de $\mathrm{Hb}-$, y el nomograma derivado para sangre humana se ha utilizado para ganado bovino, su uso no es común (Szenci E Nyiro, 1981), partiendo de que los valores de PPT $(58 \mathrm{~g} / \mathrm{L})$ y concentración de $\mathrm{Hb}$ - $(7,18 \mathrm{mmol} / \mathrm{L})$ en terneros de dos a diez semanas de edad (Szenci, 1985).

\section{Sistemas reguladores:}

Mecanismo respiratorio: Los terneros neonatos tienden hacia el estado de acidosis metabólica y respiratoria durante las horas iniciales postnatales (Hejlasz et al. 1987; Bleul et al. 2008), situación que se mejora mediante la colocación del ternero en recumbencia esternal o la suspensión de los miembros posteriores, facilitando su adaptación al nacimiento (Uystepruyst et al. 2002).

En el feto, el equilibrio ácido-base está regulado indirectamente a través de la placenta, por funciones respiratorias y renales maternas (Szenci et al. 1982). Es preciso aclarar que las vacas sometidas a estrés por calor tienden a los estados de alcalosis respiratoria, debido a la mayor frecuencia respiratoria (West, 2003).

De otro lado, el centro respiratorio en la médula oblonga controla la frecuencia respiratoria (FR). Para la regulación del $\mathrm{H}_{2} \mathrm{CO}_{3}$ la FR se aumenta, eliminando $\mathrm{CO}_{2}$ y así disminuye el $\mathrm{pH}$. Los quimiorreceptores centrales, localizados sobre la superficie ventral del bulbo raquídeo, estimulan, primariamente, la ventilación en respuesta al incremento de la $\left.\mathrm{H}^{+}\right]$del fluido cerebroespinal y, en respuesta, reduce la $\mathrm{PCO}_{2}$ (Duffin, 2005). La ventilación es inhibida cuando cae la $\left[\mathrm{H}^{+}\right]$. Los quimiorreceptores periféricos -cuerpos carotídeos- son responsables de la respuesta ventilatoria a una baja de la $\mathrm{PaCO}_{2}$. El resultado de la hipoventilación de cualquier causa, se describe con la ecuación: $\mathrm{CO}_{2}+\mathrm{H}_{2} \mathrm{O} \rightarrow \mathrm{H}_{2} \mathrm{CO}_{3} \rightarrow \mathrm{HCO}_{3}$ $+\mathrm{H}^{+}$. La elevación del $\mathrm{H}_{2} \mathrm{CO}_{3}$, como parte de la retención del $\mathrm{CO}_{2}$, produce un aumento de la concentración de ion $\mathrm{H}^{+}$, de este modo, el sistema respiratorio regula la presión parcial de $\mathrm{CO}_{2}$ en los líquidos corporales, aclarando que la tasa de extracción de $\mathrm{O}_{2}$ se incrementa durante la hipercalemia en terneros neonatos (Singh et al. 1989).

Así mismo, la resistencia de las vías aéreas centrales no cambia con el volumen pulmonar (Gustin et al. 1987); por eso, la salida de $\mathrm{O}_{2}$, la producción de $\mathrm{CO}_{2}$, la frecuencia respiratoria, la ventilación alveolar, la ventilación por minuto y la presión alveolar de $\mathrm{O}_{2}$ son más altas en bovinos, mientras que el volumen tidal y el espacio muerto fisiológico son más altos en equinos (Gallivan et al. 1989), presentándose en ganado bovino un patrón de respiración y ventilación caracterizado por una variabilidad cíclica, acoplada a la eructación (Rollin et al. 1997). 
Además, el sistema buffer $\mathrm{Hb}^{-}$del eritrocito, se adapta, especialmente, para el manejo del $\mathrm{CO}_{2}$, dado que los eritrocitos son muy permeables al $\mathrm{CO}_{2}$ y contienen altas concentraciones de anhidrasa carbónica (disminuida en terneros acidóticos y en sus madres), la cual, hidrata al $\mathrm{CO}_{2}$ transformándolo a $\mathrm{H}_{2} \mathrm{CO}_{3}$ (Szenci et al. 1984). Luego, el $\mathrm{H}_{2} \mathrm{CO}_{3}$ es disociado a $\mathrm{H}^{+}+\mathrm{HCO}_{3}{ }^{-}$; después, el $\mathrm{H}^{+}$se combina con la $\mathrm{Hb}^{-}$para formar $\mathrm{HHb}$, posteriormente, el $\mathrm{HCO}_{3}{ }^{-}$sale de la célula por difusión en intercambio por cloruro. El resultado es que el $\mathrm{CO}_{2}$ retenido es amortiguado y el $\mathrm{HCO}_{3}{ }^{-}$es liberado a la sangre en intercambio por cloruro.

Es necesario recalcar que las proteínas también sirven como amortiguadores del $\mathrm{pH}$ sanguíneo, ya que tienen grupos que pueden tomar o dar $\mathrm{H}^{+}$, como los grupos carboxilo en el C Terminal, los grupos amino en el $\mathrm{N}$ Terminal, los grupos carboxilo de cadena lateral de los ácidos glutámico y aspártico y los grupos amino $\left(\mathrm{RNH}_{3}^{+}{ }_{3} \mathrm{COO}^{-}\right)$de la cadena lateral de la lisina. De ahí la importancia de la $\mathrm{Hb}$ - en este grupo, dada su alta concentración en el eritrocito y su altísimo contenido de histidina, pues este aminoácido tiene una cadena única lateral llamada imidazole $\left(\operatorname{ImH}^{+}\right)$, que puede captar a los protones y abstraerlos de los fluidos corporales, o puede dar protones a los fluidos corporales, tratando de mantener el pH cerca a la neutralidad. Cabe anotar que los disturbios ácido-base atraviesan por dos fases: la compensación de los disturbios metabólicos es intervenida por el pulmón y su punto máximo es alcanzado en las primeras 12 a 24 horas y después opera el riñón, el cual, comienza a las 24 horas y su punto máximo es alcanzado en dos a cuatro días. La compensación de las alteraciones de naturaleza respiratoria es llevada a cabo por el riñón (Oliver, 1998).

Conviene aclarar que las concentraciones plasmáticas de $\mathrm{K}^{+}$por encima de $11,03 \mathrm{mmol} / \mathrm{L}$ se asocian con una disminución en la tensión arterial y la saturación arterial de oxígeno (Singh et al. 1989). De aquí que el $\mathrm{Cl}^{-}$y el $\mathrm{P}$ inorgánico podrían ser usados para incrementar la eficiencia del transporte del $\mathrm{O}_{2}$ en animales hipóxicos (Gustin et al. 1994), ya que la afinidad del $\mathrm{O}_{2}$ a los glóbulos rojos puede ser modulada por adición y sustracción de iones $\mathrm{Cl}^{-}$(Bucci et al. 1988). No obstante, la liberación de $\mathrm{O}_{2}$ de la sangre se puede deteriorar en terneros con diarrea dependiendo del efecto de la enfermedad sobre ciertas variables en la bioquímica sanguínea (Cambier et al. 2001), pues la acidosis in vivo y la hipercapnia, inducen una disminución en la afinidad del $\mathrm{O}_{2}$ a la $\mathrm{Hb}^{-}$en la sangre arterial, la cual, se combina a la disminución en $\mathrm{PaO}_{2}$ conduciendo a un grado de saturación de $\mathrm{Hb}^{-}$, en el compartimiento arterial (Cambier et al. 2002).

Mecanismo renal: Cuando los cationes o aniones son excretados mutuamente están acompañados en la orina por $\mathrm{HCO}_{3}{ }^{-}$o $\mathrm{H}^{+}$, respectivamente. La determinación de la excreción de $\mathrm{HCO}_{3}{ }^{-}$o $\mathrm{H}^{+}$indicará el efecto actual de la excreción renal, de tal suerte que el proceso tubular renal concluyente de esta excreción es la secreción renal de $\mathrm{H}^{+}$. Cuando el $\mathrm{H}^{+}$es excretado, la cantidad de $\mathrm{H}^{+}$libre es muy baja, de lo contrario, el $\mathrm{pH}$ de la orina sería muy ácido y la adecuada excreción de $\mathrm{H}^{+}$sería imposible; en cambio, el $\mathrm{H}^{+}$está asociado con buffers urinarios, medidos como acidez titulable (AT) o con amoníaco $\left(\mathrm{NH}_{3}\right)$ a amonio $\left(\mathrm{NH}^{+}{ }_{4}\right)$. Esta excreción renal neta de ácido (ERNA) está definida por la fórmula: ERNA $=$ Acidez Titulable $+\mathrm{NH}^{+}{ }_{4}-\mathrm{HCO}_{3}{ }^{-}$(Lunn \& McGuirk, 1990). Cuando su valor es negativo indica la cantidad de $\mathrm{HCO}_{3}{ }^{-}$eliminado del cuerpo; positivo representa la cantidad de $\mathrm{H}^{+}$eliminado por el cuerpo. Por esta razón, la ERNA es más indicativa de la carga de ácido que de los parámetros ácido-base en vacas post-parto (Hu et al. 2007). La regulación renal de la secreción de ión $\mathrm{H}^{+}$, se realiza mediante tres procesos importantes: la reabsorción de $\mathrm{HCO}_{3}^{-}$, la titulación de los buffers urinarios y la excreción del ión amonio.

La reabsorción de bicarbonato: $\mathrm{El} \mathrm{H}^{+}$secretado, se puede combinar con el $\mathrm{HCO}_{3}$ - intratubular para formar $\mathrm{H}_{2} \mathrm{CO}_{3}{ }^{-}$, el cual, se disocia en $\mathrm{CO}_{2}$ y $\mathrm{H}_{2} \mathrm{O}$, gracias a la anhidrasa carbónica presente en el borde de cepillo de las células tubulares proximales, pero no en las células del nefrón distal. De este modo, por cada $\mathrm{H}^{+}$secretado que se combina con un $\mathrm{HCO}_{3}{ }^{-}$intratubular, desaparecerá un $\mathrm{HCO}_{3}$ - intratubular adicionando un $\mathrm{HCO}_{3}{ }^{-}$a la sangre. En síntesis, la secreción total de $\mathrm{H}^{+}$es la suma del $\mathrm{HCO}_{3}{ }^{-}$filtrado que es reabsorbido, del ácido titulable que es formado y del $\mathrm{NH}_{4}{ }^{+}$que es secretado (Lunn $\mathcal{E}$ McGuirk, 1990).

Titulación de los buffers urinarios: $\mathrm{El} \mathrm{H}^{+}$secretado, se puede combinar con buffers urinarios, tales como el fosfato. Por cada $\mathrm{H}^{+}$secretado que se combina con anión fosfato inorgánico divalente $\left(\mathrm{HPO}_{4}^{-2}\right)$ para formar fosfato inorgánico dihidrógeno monovalente $\left(\mathrm{H}_{2} \mathrm{PO}_{4}^{-}\right)$, se lleva a cabo la adición de un $\mathrm{HCO}_{3}{ }^{-}$en la sangre peritubular. 
Este $\mathrm{HCO}_{3}{ }^{-}$adicional es denominado $\mathrm{HCO}_{3}{ }^{-}$regenerado y reemplaza el $\mathrm{HCO}_{3}{ }^{-}$consumido en la amortiguación de los ácidos fijos. El $\mathrm{HPO}_{4}{ }^{2-}$ es filtrado por el riñón. Como los riñones alcanzan una $\left[\mathrm{H}^{+}\right]$apreciablemente por encima del plasma, el $\mathrm{HPO}_{4}{ }^{2-}$ es filtrado y excretado como $\mathrm{H}_{2} \mathrm{PO}_{4}^{-}$y no contribuirá a la generación de nuevo $\mathrm{HCO}_{3}^{-}$(Lunn \& McGuirk, 1990).

Excreción del ion amonio: Las células del túbulo proximal producen $\mathrm{NH}_{3}$ en mayor parte por la eliminación del nitrógeno amídico de la glutamina (proceso incrementado por la acidemia y por la depleción de $\mathrm{K}^{+}$), aunque también puede tener origen en menor grado de la desaminación oxidativa de otros aminoácidos. $\mathrm{El} \mathrm{NH}_{3}$ producido existe como un gas no ionizado y se puede combinar con $\mathrm{H}^{+}$según la siguiente ecuación: $\mathrm{NH}_{3}+\mathrm{H}^{+}$ $\rightarrow \mathrm{NH}_{4}{ }^{+}$. La forma no iónica, $\mathrm{NH}_{3}$, se difunde fácilmente a través de las membranas celulares. $\mathrm{El} \mathrm{NH}_{4}{ }^{+}$es mucho menos permeable, por lo tanto, cuando $\mathrm{el}^{+}$secretado se combina con el $\mathrm{NH}_{3}$ intratubular para formar $\mathrm{NH}_{4}{ }^{+}$, promueve la secreción neta de $\mathrm{NH}_{3}$ (Atkinson E Bourke, 1987). En el asa de Henle, la alcalinización del fluido tubular causado por el mecanismo múltiple contracorriente permite la difusión no iónica elevada dentro del intersticio medular. En combinación con el transporte activo fuera del segmento grueso ascendente permite la acumulación de $\mathrm{NH}_{3}$ en el intersticio medular, fenómeno que es incrementado en la acidosis.

Luego, el $\mathrm{NH}_{3}$ pasa por difusión no iónica en el túbulo colector, un proceso favorecido por el bajo $\mathrm{pH}$ del fluido tubular. Además, el riñón regula la secreción de $\mathrm{H}^{+}$, pues la depleción del volumen circulante efectivo conduce a la liberación de aldosterona y conservación de $\mathrm{Na}^{+}$, el cual, resultará en secreción de $\mathrm{H}^{+}$, algunas veces a expensas del $\mathrm{pH}$ sistémico. La depleción de $\mathrm{K}^{+}$suprime la liberación de aldosterona (Lunn E McGuirk, 1990).

La diferencia de cationes y aniones en la dieta (DCAD):

Uno de los principales problemas en producción lechera -Sabana de Bogotá- es la presentación de la hipocalcemia periparturienta (fiebre de leche), definida como bajo calcio total $(<2,0 \mathrm{mmol} / \mathrm{L} \mathrm{u} 8,0 \mathrm{mg} / / \mathrm{dL})$ o bajo calcio ionizado sanguíneo ( $<1,0 \mathrm{mmol} / \mathrm{L}$ o $4 \mathrm{mg} / \mathrm{dL})$, con o sin signos clínicos de hipocalcemia (Oetzel, 2004), debida a los altos requerimientos de $\mathrm{Ca}^{+2}$ por parte de la vaca para producir leche. Esta enfermedad metabólica, se puede prevenir modificando la composición de la dieta (Tucker et al. 1988), ya que las cargas de los electrolitos afectan el estado ácido-base y, en últimas, el metabolismo del $\mathrm{Ca}^{2+}$. El análisis de la DIF de la dieta permite controlar mejor la DIF extracelular (Eicker, 1990). Por tal razón, la acidez o la alcalinidad de la dieta son más importantes en el control de la fiebre de leche que el mismo consumo de $\mathrm{Ca}^{2+}$ (Oetzel et al. 1988; Setia et al. 1996).

La DCAD, se define como los mili-equivalentes de $(\mathrm{Na}+\mathrm{K})-(\mathrm{Cl}+\mathrm{S})$ por kilogramo de materia seca (MS) y tiene un efecto directo sobre el estado ácido-base. La fórmula más utilizada para caracterizar la DCAD es: $\left(\left[\mathrm{Na}^{+}\right]+\left[\mathrm{K}^{+}\right]\right)-\left([\mathrm{Cl}]+\left[\mathrm{SO}_{4}{ }^{2-}\right]\right)$ (Oetzel et al. 1991). Una dieta típica para vacas secas contiene una diferencia entre cationes y aniones, alrededor de 100 a $250 \mathrm{mEq} / \mathrm{kg}$ de MS (Oetzel, 2000).

Dentro de los cationes más importantes en la dieta, se encuentran el $\mathrm{Na}^{+}$, el $\mathrm{K}^{+}$, el Ca ${ }^{2+}$ y el magnesio $\left(\mathrm{Mg}^{2+}\right)$; los aniones más importantes son el $\mathrm{Cl}^{\text {; }}$, el azufre y el $\mathrm{P}$, siendo el cloruro de amonio $\left(\mathrm{NH}_{4} \mathrm{Cl}\right)$ la sal con más poder acidificante. Una concentración de $\mathrm{NH}^{+}{ }_{4}$ de 11,7 a $58,7 \mathrm{mmol} / \mathrm{L}$ de orina es considerado como un límite tolerable (Lebeda, 1984), mientras que la concentración de lactato en plasma normal en ganado bovino alimentado con dieta rica en granos es de 1,6-8,2mmol Lactato/L, del cual del 16 al $41 \%$ es el D-isomero (Lunn E McGuirk, 1990). Es importante resaltar que las vacas multíparas son menos tolerantes a la acidosis alimentaria que las vacas primerizas (Szenci et al. 1982).

En el estrés por calor y el elevado consumo de agua con una elevada DCAD merecen especial atención, pues en situaciones de trópico, temperatura ambiental elevada, las vacas lecheras necesitan mayor contribución adicional de minerales para subsanar la ingesta reducida de MS y la pérdida de electrolitos, ya que el sudor de los bovinos es abundante en $\mathrm{K}^{+}$(West, 2003); una mayor DCAD podría mejorar el metabolismo ruminal del $N$ (Wildman et al. 2007). Otras enfermedades relacionadas a la acidosis metabólica, tales como laminitis y cetoacidosis, pueden ser influenciadas por una elevada DCAD en la lactación (Block, 1994). De allí que incrementando la DACD de 180 a $520 \mathrm{mEq} / \mathrm{kg}$, se aumenta tanto la ingesta de MS como la producción láctea (Sanchez $\mathcal{E}$ Block, 2000). El consumo reducido de materia seca (con balance energético negativo secundario antes del 
parto) es común cuando la orina está sobrecidificada (Oetzel, 2004).

De manera que la manipulación de la DCAD resulta en cambios menores en el $\mathrm{pH}$ sanguíneo, pues el riñón y los huesos compensan el mantenimiento del pH sanguíneo normal (Delaquis E Block, 1995b). Por lo general, la DCAD es reducida con el uso de sales aniónicas que contienen relativamente más $\mathrm{Cl}^{-}$y $\mathrm{S}^{-2}$ que $\mathrm{Na}^{+}$y $\mathrm{K}^{+}$, reduciendo el $\mathrm{pH}$ urinario y el $\mathrm{HCO}_{3}{ }^{-}$ plasmático (Oetzel et al. 1991; Tucker et al. 1988). Por ejemplo, dietas fuertemente aniónicas (baja DCAD) son acidogénicas, pero el $\mathrm{pH}$ sanguíneo es reducido insignificantemente permaneciendo dentro de los límites fisiológicos. Además, la excreción de $\mathrm{Ca}^{2+}$ urinario es mucho más alta y la excreción de $\mathrm{HCO}_{3}$ - mucho más baja en vacas alimentadas con dietas aniónicas que en vacas alimentadas con dietas catiónicas (Van Mosel et al. 1993).

Similarmente, las dietas catiónicas (alta DCAD) son alcalo-génicas, pero tienen un efecto pequeño sobre el pH sanguíneo porque la orina pasa a ser más alcalina, siendo el pH urinario un indicador biológico preciso para determinar si la dosis de aniones debe ser incrementada, hasta que el $\mathrm{pH}$ urinario alcance el rango óptimo (Vagnoni E Oetzel, 1998; Seifi et al. 2004). Un pH urinario bajo $(<5,5)$ sitúa a la vaca en riesgo de acidosis ruminal subaguda (Oetzel, 2004) y sugiere que la dosis de aniones puede ser reducida sin comprometer la prevención de fiebre de leche (Oetzel, 2000), dado que una dieta alcalo-génica incrementaría la disponibilidad de $\mathrm{Na}^{+}$y $\mathrm{K}^{+}$para la absorción digestiva trayendo consigo un ion de carga negativa. La fuerte relación negativa entre el $\mathrm{pH}$ urinario y la ERNA en vacas alimentadas con dietas que contienen sales aniónicas, sugieren que el $\mathrm{pH}$ urinario es una herramienta útil para evaluar el grado de acidosis metabólica (Vagnoni E Oetzel, 1998; Gelfert et al. 2006). $\mathrm{El}$ efecto del momento post-alimentación sobre el $\mathrm{pH}$ urinario es mínimo si el acceso al alimento ha sido adecuado durante todo el día (Oetzel, 2004).

Finalmente, los cambios en la concentración de $\mathrm{Ca}^{2+}$ ionizado en terneros de vacas de primera lactación en gran parte son atribuibles a la acidosis perinatal (Szenci et al. 1994). La reducción de mEq de dieta $\left(\left[\mathrm{Na}^{+}+\mathrm{K}^{+}\right]-\left[\mathrm{Cl}^{-}\right.\right.$ $+\mathrm{SO}_{4}=$ ]) a $-4 \mathrm{mEq} \mathrm{kg}-1$ en $\mathrm{MS}$ afecta algunos parámetros de la formación del hueso, sin elevar la resorción ósea (Van Mosel et al. 1994), mientras que las sales de dietas aniónicas $\left(\mathrm{MgSO}_{4} \cdot 7 \mathrm{H}_{2} \mathrm{O}+\mathrm{NH}_{4} \mathrm{Cl} ; \mathrm{MgSO}_{4} \cdot 7 \mathrm{H} 2 \mathrm{O}\right.$ $+\mathrm{CaCl}_{2} \cdot 2 \mathrm{H}_{2} \mathrm{O}+\mathrm{CaSO}_{4}$ ) incrementan la concentración ruminal de $\mathrm{NH}_{3}$, probablemente, a causa del contenido más alto de NNP en esas dietas. Una dieta basada en henolaje de alfalfa, comparada con una dieta basada en ensilaje con similar diferencia entre aniones y cationes, resulta en diferente metabolismo mineral y de agua, sin afectar el estado ácido-base de vacas en la lactación temprana (Delaquis \& Block, 1995a). Sin embargo, se puede presentar acidosis metabólica en vacas lecheras gestantes durante la época seca (noviembre-abril) alimentadas con ensilajes, subproductos azucareros y pastos de regular calidad (Viamonte et al. 1992). Vacas alimentadas con dietas que contienen sales de $\mathrm{NH}^{+}{ }_{4}$ presentan concentraciones más altas de $\mathrm{Ca}^{2+}$ ionizado y Ca ${ }^{2+}$ total al momento del parto.

Las concentraciones séricas de $\mathrm{Mg}^{2+}, \mathrm{P}, \mathrm{Na}^{+}, \mathrm{K}^{+}$y $\mathrm{Cl}^{-}$el día del parto no se afectan por la dieta (Oetzel et al. 1988). Por último, para vacas lecheras adultas, el $\mathrm{NaHCO}_{3}$ y el propionato de $\mathrm{Na}^{+}$son igualmente efectivos en la corrección del estado ácido-base. El propionato de $\mathrm{Na}^{+}$puede ser considerado un tratamiento más efectivo de acidosis metabólica en enfermedades, tales como cetosis, porque el propionato adicionado puede servir como una fuente de energía para la vaca (Bigner et al. 1997).

\section{CONCLUSIONES}

Todos los cambios en el pH sanguíneo tanto en bovinos saludables como en fermos ocurren a través de cambios en tres variables: $\mathrm{PCO}_{2}$, la concentración de electrolitos y la concentración de ácidos débiles totales. Ni la $\left[\mathrm{H}^{+}\right]$ni la $\left[\mathrm{HCO}_{3}{ }^{-}\right]$pueden cambiar, a menos que una o más de las tres variables varíe. Aunque calcular el valor exacto de la DIF es complicado, se puede estimar su valor aproximado mediante la fórmula $\left(\left[\mathrm{Na}^{+}\right]+\left[\mathrm{K}^{+}\right]\right)-([\mathrm{Cl}]+[$ lactato $])=\mathrm{DIF}$. Queda a juicio del clínico, la selección del modelo fisicoquímico para la evaluación del estado ácidobase del paciente, de acuerdo a la disponibilidad de herramientas de laboratorio y a los hallazgos clínicos y de laboratorio encontrados. Las muestras, se deben recolectar y conservar, adecuadamente y con extremo cuidado minimizando cualquier posible alteración en los valores de $\mathrm{pH}$, gases sanguíneos y electrolitos, evitando así lecturas erróneas. Si la concentración de proteínas plasmáticas totales es normal, se sugiere emplear el modelo de Henderson-Hasselbach, estimando la 
presencia de aniones no identificados, a través del cálculo de anión restante. Si la concentración de proteínas plasmáticas totales se encuentra por fuera del rango de referencia, se sugiere la utilización del modelo de iones fuertes de Stewart o el modelo de iones fuertes simplificado $\left(\mathrm{PCO}_{2}\right.$, medida $\left[\mathrm{DIF}^{+}\right]$y $\left.\left[\mathrm{A}_{\mathrm{TOT}}\right]\right)$. La manipulación de los aniones y los cationes en la dieta por medio de la adición de sales fuertemente aniónicas (baja DCAD, acidogénicas) mejoran la disponibilidad y la absorción del calcio, disminuyendo así el riesgo de fiebre de leche, siendo el $\mathrm{pH}$ urinario como un indicador biológico preciso y de fácil uso en campo.

\section{BIBLIOGRAFÍA}

ADAMS, R.; HOLLAND, M.D.; ALDRIDGE, B.; GARRY, F.B.; ODDE, K.G. 1991. Arterial blood sample collection from the newborn calf. Vet Res Commun (Países Bajos). 15(5):387-394.

ASTRUP, P.; JORGENSEN, K.; SIGGAARD ANDERSEN, O.; ENGEL, K. 1960. The acid base metabolism: a new approach. Lancet. 1(7133):1035-1037.

ATKINSON, D.E.; BOURKE, E. 1987. Metabolic aspects of the regulation of systemic $\mathrm{pH}$. Am. J. Physiol. 252:947-956.

BAJCSY, A.; BARTYIK, J.; SZENCI, O. 1999. Comparison of blood ionized calcium and Acid-Base variables in samples from different sampling sites in dairy cows. J. Vet. Med. A (Alemania). 46(4):255-259.

BAQUERO-PARRADO, J.R.; FUENTES-REYES, E.E. 2007. Fluidoterapia en ganado bovino. Revista U.D.C.A. Actualidad E Divulgación Científica (Colombia). 10(2):1-17.

BENJAMIN, M.M. 1991. Hematología: Extracción de sangre. Manual de Patología Clínica en Veterinaria. $3^{a}$ reimpresión, México, DF, Ed. Limusa, p.9-20.

BIGNER, D.R.; GOFF, J.P.; FAUST, M.A.; TYLER, H.D.; HORST, R.L. 1997. Comparison of oral sodium compounds for the correction of acidosis. J. Dairy Sci. (EEUU). 80(9):2162-2166.

BLEUL, U.; LEJEUNE, B.; SCHWANTAG, S.; KAHN, W. 2007. Blood gas and acid-base analysis of arterial blood in 57 newborn calves. Vet Rec. (Reino Unido). 161(20):688-691.

BLEUL, U.; SCHWANTAG, S; KÄHN, W. 2008. Blood gas analysis of bovine fetal capillary blood during stage II labor. Theriogenology. (EEUU) 69(2):245-251.

BLOCK, E. 1994. Manipulation of dietary cation-anion difference on nutritionally related production diseases, productivity, and metabolic responses of dairy cows. J. Dairy Sci. 77(5):1437-1450.

BUCCI, E.; FRONTICELLI, C.; ORTH, C.; MARTORANA, M.C.; AEBISCHER, L. 1988. Bovine hemoglobin as a basis for artificial oxygen carriers. Biomater Artif Cells Artif Organs (EEUU). 16(1-33):197-204.

CAMBIER, C.; CLERBAUX, T.; MOREAUX, B.; DETRY, B.; BEERENS, D. 2001. Blood oxygen binding in calves with naturally occurring diarrhea. Am. J. Vet. Res. 62(5):799-804.

CAMBIER, C.; CLERBAUX, T.; DETRY, B.; MARVILLE, V.; FRANS, A. 2002. Blood oxygen binding hypoxemic calves. Vet. Res. (Francia). 33(3):283-290.

CARLSON, G.P. 1989. Fluid, Electrolyte, and AcidBase Balance. En: Kaneko, J.J. ed. Clinical and Biochemistry of Domestic Animals. 4a Ed, San Diego, California, U.S.A., Ed. Academic Press, p.543-575.

CASTAÑEDA, R.; MORENO, C.; OLIVER, O.; DONADO, P. 2002. Acid-base balance in bovine anaplasmosis. En: Memorias: XXII World Buiatrics Congress Hannover, Alemania, agosto 18-23, Abstract 510-299.

CONSTABLE, P.D; SCHMALL, L.M; MUIR III, W.W; HOFFSIS, G.F. 1991. Respiratory, renal, hematologic, and serum biochemical effects of hypertonic saline solution in endotoxemic calves. Am. J. Vet. Res. 52(7):990-998.

CONSTABLE, P.D. 1991. Clinical assessment of renal tubular function through determination of electrolyte and creatinine concentrations. J. Vet. Intern. Med. (EEUU). 5(6):357-358. 
CONSTABLE, P.D. 1997. A simplified strong ion model for acid-base equilibria: application to horse plasma. J. Appl. Physiol. 83(1):297-311.

CONSTABLE, P.D.; STREETER, R.N.; KOENING, G.J.; PERKINS, N.R.; GOHAR, H.M. 1997. Determinants and utility of the anion gap in predicting hyperlactatemia in cattle. J. Vet. Intern. Med. 11(2):71-79.

CONSTABLE, P.D. 1999. Clinical assessment of acidbase status: Strong ion difference theory. Vet. Clin. North Am., Food Anim. Pract. 15(3):447-471.

CONSTABLE, P.D. 2000. Clinical assessment of acidbase status: comparison of the Henderson-Hasselbach and strong ion approaches. Vet. Clin. Path. (EEUU). 29(4):124.

CONSTABLE, P.D. 2002. Calculation of variables describing plasma nonvolatile weak acids for use in the strong ion approach to acid-base balance in cattle. Am. J. Vet. Res. 63(4):482-490.

CONSTABLE, P.D. 2003. Fluid and electrolyte therapy in ruminants. Vet. Clin. North Am., Food Anim. Pract. 19(3):557-597.

CONSTABLE, P.D.; STAEMPFLI, H.R. 2004. Using the simplified strong ion approach to determine the mechanism for an acid-base disturbance in calves. En: Memorias: 23rd World Buiatrics Congress, Quebec, Canada, julio 11-16, abstract 026 (3364).

DELAQUIS, A.M.; BLOCK, E. 1995a .The effects of changing ration ingredients on acid-base status, renal function, and macromineral metabolism. J. Dairy Sci. 78(9):2024-2039.

DELAQUIS, A.M.; BLOCK, E. 1995b; Acid-base status, renal function, water, and macromineral metabolism of dry cows fed differing in cation-anion difference. J. Dairy Sci. 78(3):604-619.

DIRKSEN, G.U.; SMITH, M.C. 1987. Acquisition and analysis of bovine rumen fluid. Bovine Pract. (EEUU). 22:108-116.
DUFFIN, J. 2005. The role of acid-base balance in the chemoreflex control of breathing. J. Appl. Physiol. 99(6):2255-2265.

EICKER, S.W. 1990. An Introduction to Strong Ion Difference. Vet. Clin. North Am. Food Anim. Pract. 6(1):45-49.

EWASCHUK, J.B.; NAYLOR, J.M.; ZELLO, G.A. 2003. Anion gap correlates with serum D- and DL-lactate concentration in diarrheic neonatal calves. J. Vet. Intern. Med. 17(6):940-942.

FELDMAN, B.F.; ROSENBERG, D.P. 1981. Clinical use of anion gaps in veterinary medicine. J. Am. Vet. Med. Assoc. 178(4):396-398.

FENCL, V.; JABOR, A.; KAZDE, A.; FIGGE, J. 2000. Diagnosis of metabolic acid-base disturbances in critically ill patients. Am. J. Respir. Crit. Care Med. 162(2):2246-2251.

FIGGE, J.; ROSSING, T.H.; FENCL, V. 1991. The role of serum proteins in acid-base equilibria. J. Lab. Clin. Med. (EEUU). 117(6):453-467.

FLEMING, S.A.; HUNT, E.L.; RIVIERE, J.E.; ANDERSON, K.L. 1991. Renal clearance and fractional excretion of electrolytes over four 6-periods in cattle. Am. J. Vet. Res. 52(1):5-8.

FLEMING, S.A.; HUNT, E.L.; BORWNIE, C.; RAKES, A.; MCDANIEL, B. 1992. Fractional excretion of electrolytes in lactating dairy cows. Am. J. Vet. Res. 53(2):222-224.

FUNK, G.C. 2007. Stewart's acid-base approach. Wien Klinik Wochenschr. (Austria). 119(13-14):390403.

GABOW, P.A.; KAEHNY, W.D.; FENNESSEY, P.V.; GOODMAN, S.I.; GROSS, P.A. 1980. Diagnostic importance of an increased serum anion gap. New Engl. J. Med. (EEUU). 303(15):854-858.

GABOW, P.A. 1985. Disorders associated with an altered anion gap. Kidney Int. (EEUU). 27(2):472-483. 
GALLIVAN, G.J.; MCDONELL, W.N; FORREST, J.B. 1989. Comparative ventilation and gas exchange in the horse and the cow. Res. Vet Sci. (Reino Unido). 46(3):331-336.

GARRET, E.F.; PEREIRA, M.N.; NORDLUND, A.V.; ARMENTANO, L.E.; GOODGER, W.J. 1999. Diagnostic methods for the detection of subacute ruminal acidosis in dairy cows. J. Dairy Sci. 82(6):1170-1178.

GARRY, F.B; HULL, B.L; RINGS, D.M; KERSTING, K; HOFFSIS, G. 1985. Prognostic value of anion gap calculation in cattle with abomasal volvulus: 58 cases (1980-1985). J. Am. Vet. Med. Assoc. 192(8):1107-1112.

GELFERT, C.C.; PASSFELD, M.; LÖPTIEN, A.; MONTAG, N.; BAUMGARTNER, W.; STAUFENBIEL, R. 2006. Experimental studies on the impact of an increased dose of anionic salts on the metabolism of dairy cows. Vet.Q. (Paises Bajos). 28(4):130-139.

GEISHAUSER, T.; MANNHARDT, K. 1994. Methods for the determination of $\mathrm{pH}$ value and redox potential in the rumen fluid of adult cattle. Tierärztl. Praxis. (Alemania). 22(5):443-449.

GROUTIDES, C.; MICHELL, A.R. 1990. Evaluation of acid-base disturbances in calf diarrhea. Vet. Rec. 126(2):29-31.

GUSTIN, P.; LOMBA, F.; BAKIMA, M.; LEKEUX, P.; VAN DE MOESTIJNE, K.P. 1987. Partitioning of pulmonary resistance in calves. J. Appl. Physiol. 62(5):1826-1831.

GUSTIN, P.; DETRY, B.; CAO, M.L.; CHENUT, F.; ROBERT, A.; ANSAY, M. 1994. Chloride and inorganic phosphate modulate binding of oxygen to bovine red blood cells. J. Appl. Physiol. 77(1):202-208.

HALPERIN, M.L.; GOLDSTEIN, M.B. 1999. The Clinical Approach to Acid-Base Disorders. Fluid, Electrolyte, and Acid-Base Physiology. 3a Ed, Philadelphia, W.B. Saunders, 52p.

HASSELBALCH, K.A. 1916. Die Berechnung der Wasserstoffzahl des Blutes auf der freien und gebundenen Kohlensäure desselben, und die Sauerstoffbindung des Blutes als Funktion der Wasserstoffzahl. Biochem. 78:112-144.

HEJLASZ, Z.; NICPON, J.; RAULUSZKIEWICZ, S., SAMBORSKI, Z. 1987. Buffers systems, electrolytes, $\mathrm{pH}$, and erythrocyte indices in the blood of cows and calves in the perinatal period. Pol. Arch. Weter. (Polonia). 25(2-3):225-235.

HU, W.; MURPHY, M.R.; CONSTABLE, P.D.; BLOCK, E. 2007. Dietary cation-anion difference effects on performance and acid-base status of dairy cows postpartum. J. Dairy Sci. 90(7):3367-3375.

KASARI, T.R.; NAYLOR, J.M. 1986. Further studies on the clinical features and clinicopathological findings of a síndrome of metabolic acidosis with minimal dehydration in neonatal calves. Can. J. Vet. Res. 50(4):502-508.

KASARI, T.R. 1999. Metabolic acidosis in calves. Vet. Clin. North Am., Food Anim. Pract. 15(3):472-486.

KRAUT, J.A.; MADIAS, N.E. 2007. Serum anion gap: its uses and limitations in clinical medicine. Clin. J. Am. Soc. Nephrol. 2(1):162-174.

LEBEDA, M. 1984. Concentration of ammonia in the urine of dairy cows given green feed rations and winter feed rations. Vet. Med. (Praha) (República Checa). 29(7):387-400.

LISBÔA, J.A.N.; BENESI, F.J.; LEAL, M.L.R.; TEIXEIRA, C.M.C. 2003. Efeito do tempo após a ingestão de leite sobre o equilíbrio ácido-básico de bezerros. Arqu. Bras. Med. Vet. e Zoot. 55(6): 763-765.

LORENZ, I. 2004. Investigations on the influence of serum D-lactate levels on clinical signs in calves with metabolic acidosis. Vet. J. 168(3):323-327.

LORENZ, I.; VOGT, S. 2006. Investigations on the association of d-lactate blood concentrations with the outcome of therapy of acidosis, and with posture and demeanors in young calves with diarrhea. J. Vet. Med. A. 53(9):490-494. 
LUNN, D.P.; MCGUIRK, S.M. 1990. Renal regulation and acid-base balance in ruminants. Vet. Clin. North Am., Food Anim. Pract. 6(1):1-28.

MICHELL, A.R.; BYWATER, R.J.; CLARKE, A.W.; HALL, L.W.; WATERMAN, A.E. 1991. Regulación de los fluidos corporales. Fluidoterapia Veterinaria. 1a Ed, Edit. Acribia, Zaragoza, ESPAÑA. p.1-21.

NAPPERT, G.; NAYLOR, J.M. 2001. A comparison of pH determination methods in food animal practice. Can. Vet. J. 42(5):364-367.

NAYLOR, J.M. 1987. Evaluation of the total carbon dioxide apparatus and $\mathrm{pH}$ meter for the determination of Acid-Base status in diarrheic and healthy calves. Can. Vet. J. 28(1-2):45-48.

NEIGER, R.D.; HAGEMOSER, W.A. 1985. Renal percent clearance ratios in cattle. Vet. Clin. Pathol. (EEUU). 14(1):31-35.

OETZEL, G.R.; OLSON, J.D.; CURTIS, C.R.; FETTMANN, M.J. 1988. Ammonium chloride and ammonium sulfate for prevention of parturient paresis in dairy cows. J. Dairy Sci. 71(12):3302-3309.

OETZEL, G.R.; FETTMANN, M.J.; HAMAR, D.W.; OLSON, J.D. 1991. Screening of anionic salts for palatabillity, effects on acid-base status, and urinary calcium excretion in dairy cows. J. Dairy Sci. 74(3):965-971.

OETZEL, G.R. 2000. Management of dry cows for the prevention of milk fever and other mineral disorders. Vet. Clin. North Am., Food Anim. Pract. 16(2):369-386.

OETZEL, G.R. 2004. Monitoring and testing dairy herds for metabolic disease. Vet. Clin. North Am., Food Anim. Pract. 20(3):651-674.

OLIVER, O.E. 1998. Balance Hídrico, Electrolítico y Acido-Base: Implicaciones terapéuticas. En: Memorias Equilibrio Hídrico-electrolítico y Acido-Base en Medicina Veterinaria. Santa Fe de Bogotá D.C, Facultad de Medicina Veterinaria, U.N. Colombia, Abril 24 y 25, p.42.
QUINTARD, H.; HUBERT, S.; ICHAI, C. 2007. What is the contribution of Stewart's concept in acid-base disorders analysis? Ann. Franç. d'Anesthésie et de Réanimation (Francia). 26(5):423-433.

RADOSTITIS, O. 2002. Exploración clínica del aparato digestivo. En Radostitis, O.M; Mayhew, I.G.J., Houston, D.M. eds. Examen y Diagnóstico Clínico en Veterinaria. 1a ed, Ed. Harcourt, España. p.349-468.

RAMÍREZ, G.; BITTLE, P.A.; COLICE, GL.; SANTACRUZ, R.; HIDALGO, A. 1992. Blood biochemical characteristics of cattle at sea level and moderately high altitude (3.000m). Am. J. Vet. Res. 53(4):54-550.

REHM, M.; CONZEN, P.F.; PETER, K.; FINSTERER, U. 2004. The Stewart model. „Modern“ approach to the interpretation of the acid-base metabolism. Anaesthesist (Alemania). 53(4):347-357.

ROEDER, B.L.; CLARK, F.D. 1995. Determination of serum ionized calcium concentration in dairy cattle after frozen anaerobic storage. Vet. Clin. Pathol. 24(2):44-48.

ROLLIN, F.; DESMECHT, D.; GENICOT, B.; LINDEN, A.; LOMBA, A. 1997. Ventilatory effects of the single-breath $\mathrm{CO} 2$ test, compared with eructation, in cattle. Am J Vet Res. 58(3):310-316.

ROUSSEL, A.J.; WHITNEY, M.S.; COLE, D.J. 1997. Interpreting a bovine serum chemistry profile: Part 2. Vet Med. 92(6):559-566.

SÁNCHEZ, W.; BLOCK, U. 2000. Update on DCAD: Milking and transition cows. Proc. Calif. Anim. Nutr. Conf. Fresno. CA. p.106-125.

SATTLER, N.; FECTEAU, G.; COUTURE, Y.; TREMBLAY, A. 2001. Determination of the potassium balances in dairy cows and the examination of daily and lactation period-associated variations. Can. Vet. J. 42(2):107-115.

SEIFII, H.A.; MOHRI, M.; KALAMATI-ZADEH, J., 2004. Use of pre-partum urine $\mathrm{pH}$ to predict the risk of milk fever in dairy cows. Vet. J. (Reino Unido). 167(3):281-285. 
SETIA, M.S.; SINGH, A.; KAHLON, R.S.; RANDHAWA, S.S. 1996. Alterations in the systemic acid-base status and blood gas dynamics during progressive hypocalcaemia in cow calves. Indian J. Exp. Biol. 34(4):375-376.

SHERLOCK, M.; HEALY, A.M.; DOHERTY, M.L. 2003. Acid-base balance in field cases of bovine babesiosis. Vet. Rec. 152:687-688.

SIMPSON, D.F.; ERB, H.N.; SMITH, D.F. 1985. Base excess as a prognostic and diagnostic indicator in cows with abomasal volvulus or right displacement of the abomasum. Am. J. Vet. Res. 46(4):796797.

SINGH, A.; RANDHAWA, S.S.; SETIA, M.S. 1989. Alterations in acid-base status and blood gas dynamics during progressive hyperkalemia in neonatal calves. Res. Vet. Sci. 46(2):277-279.

STAEMPFLI, H.R.; PETRIE, J.P.; LUMSDEN, J.H. 1994. The weak acid concentration of plasma in Holstein calves. En: Proceedings VI Congress International Society for Animal Clinical Biochem. p.76.

STAEMPFLI, H.R. 2005. Role of electrolytes in acid-base balance: theory and practicality. Proceedings of the ACVIM (American College Veterinary Internal Medicine) Forum Baltimore. Electronic Proceedings.

STEWART, P.A. 1983. Modern quantitative acid-base chemistry. Can. J. Physiol. Pharmacol. 61(12):14441461.

STOCKER, H.; LUTZ, H.; KAUFMANN, C.; RÜSCH, P. 1999. Acid-base disorders in milk-fed calves with chronic indigestion. Vet. Rec. 145(12):340-346.

STOCKHMAN, S.L., SCOTT, M.A. 2002. Blood gases, blood $\mathrm{pH}$, and strong ion difference. Veterinary Clinical Pathology. 1a ed. Blackwell Publishing. lowa, U.S.A. p.381-400.

SZENCI, O.; NYIRO, K. 1981. Assessment of the parameters controlling the acid-base status of newborn calves. A modification of Van Slyke's equation. Acta Vet. Acad. Sci. Hung. 29(2):153-157.
SZENCI, O.; KUTAS, F.; HARASZTI, J. 1982. Influence of induced maternal acidosis on the acid-base balance of the newborn calf. Acta Vet. Acad. Sci. Hung. 30(1-3):71-77.

SZENCI, O. 1982. Correlations between muscle tone and acid-base balance in newborn calves: experimental substantiation of a simple new score system proposed foe neonatal status diagnosis. Acta Vet. Acad. Sci. Hung. 30(1-3):80.

SZENCI, O.; GÀLFI, P.; LAJCSÀK, A. 1984. Comparison of Carbonic Anhydrase In Neonatal and Maternal Red Blood Cells with different Levels of Acidosis in Newborn Calves. J. Vet. Med. A. 31(6):437-440.

SZENCI, O. 1985. Role of acid-base disturbances in perinatal mortality of calves. Acta Vet. Acad. Sci. Hung. 33(3-4):205-220.

SZENCI, O.; BRYDL, E.; BAJCSY, C.A. 1991. Effect of storage on measurement of ionized calcium and acid-base variables in equine, bovine, ovine, and canine venous blood. J. Am. Vet. Med. Assoc. 199(9):1167-1169.

SZENCI, O.; CHEW, BP.; BAJCSY, C.A.; SZABO, P.; BRYDL, E. 1994. Total and ionized calcium in parturient dairy cows and their calves. J. Dairy Sci. 77(4):1100-1105.

TUCKER, W.B.; HARRISON, G.A.; HEMKEN, R.W. 1988. Influence of dietary cation-anion balance on milk, blood, urine, and rumen fluid in lactating dairy cattle. J. Dairy Sci. 71(2):346-354.

TYLER, H.; RAMSEY, H. 1991. Hipoxia in neonatal calves: effects on selected metabolic parameters. J. Dairy Sci. 74(6):1957-1962.

ULUTAS, B.; SAHAL, M. 2005. Urinary GGT/creatinine ratio and fractional excretion of electrolytes in diarrhoeic calves. Acta Vet. Acad. Sci. Hung. 53(3):351-359.

UYSTEPRUYST, C.; COGUE, J.; DORTS, T.; HARMEGNIES, N.; DELSEMME, M. 2002. Sternal recumbency or suspension by the hind legs immediately 
after delivery improves respiratory and metabolic adaptation to extrauterine life in newborn calves delivered by cesarean section. Vet. Res. 33(6):709724.

VAGNONI, D.B.; OETZEL, G.R. 1998. Effects of Dietary Cation-Anion Difference on the Acid-Base Status of Dry Cows. J. Dairy Sci. 81(6):1643-1652.

VAN MOSEL, M.; VAN`T KLOOSTER, A.T.; VAN MOSEL, F.; VAN DER KUILEN, J. 1993. Effects of reducing dietary $\left(\left[\mathrm{Na}^{+}+\mathrm{K}^{+}\right]-\left[\mathrm{Cl}^{-}+\mathrm{SO}_{4}{ }^{=}\right]\right)$on the rate of calcium mobilization by dairy cows at parturition. Res Vet Sci. 54(1):1-9.

VAN MOSEL, M.; WOUTERSE, H.S.; VAN'T KLOOSTER, A.T. 1994. Effects of reducing dietary $\left(\left[\mathrm{Na}^{+}\right.\right.$ $\left.\left.+\mathrm{K}^{+}\right]-\left[\mathrm{Cl}^{-}+\mathrm{SO}_{4}=\right]\right)$ on bone in dairy cows at parturition. Res. Vet Sci. 56(3):270-276.

VIAMONTE, M.I.; FAJARDO, L.C.; RONDON, G. 1992. Estado ácido-básico en hembras bovinas lecheras con diferentes estados reproductivos. Rev. Cubana Cienc. Vet. 23(2-3):113-115.

WEST, J.W. 2003. Effects oh Heat-Stress on Production in Dairy cattle. J. Dairy Sci. 86(3):2131-2144.
WHITEHAIR, K.J.; HASKINS, S.C.; WHITEHAIR, J.G.; PASCOE, P.J. 1995. Clinical applications of quantitative acid-base chemistry. J. Vet. Intern. Med. 9(1):1-11.

WILKES, P. 1998. Hypoproteinemia, strong-ion difference, and acid-base status in critically ill patients. J. Appl. Physiol. 84(5):1740-1748.

WILSON, G.D.; HUNTER, J.T.; DERRICK, G.H.; AITKEN, W.M.; KRONFELD, D.S. 1977. Fetal and maternal plasma electrolytes, blood gases, and $\mathrm{pH}$ in dairy cattle during late pregnancy. J. Dairy Sci. 60(6):1110-1116.

WILDMAN, C.D.; WEST, J.W.; BERNARD, K. 2007. Effects of Dietary Cation-Anion Difference and Potassium to Sodium Ratio on Lactating Dairy Cows in Hot Weather. J. Dairy Sci. 90(2):970-977.

WINTER, S.D.; PEARSON, J.R.; GABOW, P.A.; SCHULTZ, A.L.; LEPOFF, R.B. 1990. The fall of the serum anion gap. Arch. Intern. Med. (EEUU). 150(2):311-313.

Recibido: Febrero 29 de 2008

Aceptado: Octubre 14 de 2008 